\title{
Preparation of a Manual for the Organization of the Work of the Nucleus of Socialist Agroecological Training "Indio Rangel" (NUFASIR) Bolivarian Republic of Venezuela
}

\author{
Delvis Valdes Zayas ${ }^{1,}$, , Anayansis Albert Rodriguez ${ }^{2}$, Belen Arteaga Calanche ${ }^{3}$, \\ Eduard Rangel $\operatorname{Roa}^{3}$ \\ ${ }^{1}$ Department of Development, Municipal University Center of Trinidad, University Jose Marti Perez of Sancti Spiritus, Trinidad, Cuba \\ ${ }^{2}$ Municipal University Center of Trinidad, University Jose Marti Perez of Sancti Spiritus, Trinidad, Cuba \\ ${ }^{3}$ Nucleus of Socialist Agroecological Training "Indio Rangel" (NUFASIR), Aragua Estate, Bolivarian Republic of Venezuela
}

Email address:

delvisvz71@gmail.com (D. V. Zayas)

${ }^{*}$ Corresponding author

\section{To cite this article:}

Delvis Valdes Zayas, Anayansis Albert Rodriguez, Belen Arteaga Calanche, Eduard Rangel Roa. Preparation of a Manual for the Organization of the Work of the Nucleus of Socialist Agroecological Training "Indio Rangel" (NUFASIR) Bolivarian Republic of Venezuela. International Journal of Science, Technology and Society. Vol. 9, No. 1, 2021, pp. 1-13. doi: 10.11648/j.ijsts.20211001.11

Received: January 10, 2021; Accepted: January 20, 2021; Published: March 3, 2021

\begin{abstract}
Within the framework of the collaboration carried out between the Republic of Cuba and the Bolivarian Republic of Venezuela, there are close working ties between the University Center of Trinidad, Cuba and the Indio Rangel Socialist Agroecological Training Center of the Bolivarian Republic of Venezuela, within the framework of this professional collaboration, the aforementioned entity, requested the Cuban side, the support in the elaboration of a methodological document, which would allow the organization and better planning of the human resources in the aforementioned institution. This is why Cuban and Venezuelan specialists participate in the preparation of this manual, which constitutes a tool for the orientation and facilitation in the action of labor resources, becoming a document of consultation and mandatory analysis of the managers and workers of this entity, is structured in Eight Chapters, which are adjusted to the international standards in this matter, in addition to strict adherence to compliance with what is established in terms of labor organization at the international level and at the level of the Bolivarian Republic of Venezuela, in these chapters you can find from the characterization of the main work areas, to the functions that each worker must perform, in each job that the entity needs, a methodology devised to carry out a methodology also appears as a novelty within the document. evaluation of labor performance, in a more accurate way and adjusted to the conditions of this institution, and at the end a chapter has been dedicated to everything related to material responsibility, levels of access to the areas and the way of preservation of the themselves, as any document of this type is subject to change and adaptation of the law.
\end{abstract}

Keywords: Collaboration, Organization, Methodology, Legislation and Direction

\section{Introduction}

Every organization must have a set of standards, principles, tools and labor laws in place that allow it to function properly. They have a subordination and coherence with the Magna Carta of the country of origin, with its labor law and with the will of the people [1].

The Bolivarian Republic of Venezuela has an Organic Law of Labor, Workers and Workers (LOTTT), appeared in
Official Gazette No. 6,076 Extraordinary of May 7, 2012, in its Statement of Motives it states: The Organic Law of Labor arose as a consequence of the important contradictions that arose with the establishment of the neoliberal model, which in Venezuela experienced its moment of greatest intensity starting in 1989. The privatization wave of that time, among other economic measures of great social impact, promoted a series of social struggles that led to the rearrangement of a series of scattered regulations in various norms of different categories, thus renovating the existing social contract. In this 
context, the Bolivarian Republic of Venezuela takes a step forward in its purpose of ensuring the rights of the population, granting a legal basis to the constitutional mandates received in 1999 and introducing an important progressive interpretation of them, heading towards a society eminently fair, ethical, moral and democratic, as is clear from the mandate of the social doctrine of the Liberator, Simón Bolívar. In this law itself, in Title I it says: the right to work and the duty to work of people are enshrined according to their capacities and aptitudes, which includes people with disabilities. Equality and gender equity is also guaranteed in the exercise of the right to work, and indigenous languages are incorporated as official in the employment relationship, and therefore the obligation to communicate the provisions that are communicated in said languages to the indigenous workers. Work is prohibited for people before the age of fourteen, and accepts the provisions of the Organic Law for the Protection of Boys, Girls and Adolescents [2, 7].

Later in this chapter it is stated:, Law enforcement guarantees are incorporated by granting administrative and judicial authorities empowered to ensure that their administrative or judicial decisions restore the infringed legal situation of a labor nature, including the use of force. public, in those situations that may warrant it. It also streamlines and simplifies the administration of labor justice, and also establishes the objective responsibility of the employer in relation to the guarantees that the law requires with its workers and with the country, with special emphasis on health and job security [7]. The LOTTT promotes and protects popular initiative at work, facilitating the development of socially owned work entities and any other form of community association for work managed in a participatory and leading way by workers.

In Chapter III, it says: The LOTTT, incorporates the notion that wealth is a social product generated mainly by male and female workers and therefore it is established that its fair distribution must guarantee a dignified life with their families. Along the same lines, it attributes to the State the responsibility of protecting wages, as well as protecting and strengthening family income, in co-responsibility with society and the organizations of the People's Power, for which the Executive may, among other measures, decree wage increases, making extensive consultations and knowing the opinions of the different social organizations and institutions in socio-economic matters. The charging of bank commissions to payroll accounts and the establishment of conditions for the opening and maintenance of this type of account are prohibited.

Later, in Title I, Chapter II, Article 18, it states that the interpretation and application of this Law will be guided by the following principles:

1. Social justice and solidarity.

2. The intangibility and progressiveness of labor rights and benefits, so they will not suffer deterioration and will tend to their progressive development.

3. In labor relations, reality prevails over forms or appearances.
4. Labor rights are inalienable. Any action, agreement or agreement that implies the waiver or impairment of these rights is void.

5. When there are doubts about the application or concurrence of several norms or in the interpretation of a certain norm, the one most favorable to the worker will be applied. The adopted standard will be applied in its entirety.

6. Any measure or act of the employer contrary to the Constitution of the Bolivarian Republic of Venezuela or this Law is null and void and does not generate any effect.

7. All types of discrimination for reasons of age, race, sex, social condition, creed or those that undermine the right to equality before the law and for any other condition are prohibited.

8. The work of adolescents in tasks that may affect their integral development in any way is prohibited. The State will protect them against any economic or social exploitation.

A manual is the document that contains the description of activities that must be followed in the performance of the functions of an administrative unit, or of two or more of them. The manual also includes the positions or administrative units that intervene, specifying their responsibility and participation. In it, the basic information regarding the operation of all administrative units is recorded and transmitted without distortion, it facilitates auditing, evaluation and internal control and monitoring, awareness in employees and their bosses that the work is done. is performing or not performing properly [11].

It is essential to know what the organization is of work and what are the factors and processes involved in her, in order to prevent all these problems potentiated by the current world economic crisis, the changes organizational and context where institutions develop, improve the health of workers, and create healthy and effective organizations [8].

Recisely taking into account all the aforementioned, and specifically the eight previous principles, with the realization of this document it has been intended:

General purpose

Prepare a manual for the organization of work in NUFASIR, for the efficient use of its human resources.

To achieve the objective stated above, it is necessary to:

Specific objectives

1. Determine the NUFASIR staff.

2. Establish position qualifier and functions.

3. Establish the official organization chart of NUFASIR.

4. Establish norms, conditions and the contracting process for entering NUFASIR.

5. Establish methodology for planning and control of work in NUFASIR.

6. Delimit areas and levels of responsibility and access by NUFASIR work areas.

7. Establishment of labor protection and hygiene standards.

8. Establishment of disciplinary and sanction regulations 
for NUFASIR.

9. Establish duties and rights of workers in NUFASIR.

10. Establish methodology for evaluating job performance in NUFASIR.

11. Establish a Stimulation System.

Development

\section{Determination of the NUFASIR Work Force}

For the preparation of the NUFASIR workforce, it is necessary to start from basic principles that are included in the LOTTT and that at the same time are a reflection of the needs and aspirations of the people that appear in the Constitution of the Bolivarian Republic of Venezuela, in its construction process of the declared socialist model, which are: Full social inclusion, non-discrimination, guarantee of rights, maximum social equity, rational use of resources, capacities and aptitudes [2].

On the other hand, it is necessary to start from the corporate purpose for which the NUFASIR is conceived, knowing that this corporate purpose has two fundamental components that are: The training and the productive; In addition to taking into account the total area covered by the physical structure of NUFASIR, which demands its own maintenance and growth needs, being also very objective when establishing a template that is functional and guarantees compliance with the objectives set by NUFASIR
In its highest aspiration to guarantee its corporate purpose, and leaving aside the burdens that hinder inflated workforce and corruption, then it is necessary to be consistent when planning the human resources of this institution.

Foreigners and cadres of the nucleus in need of lodging, Figure 1 .

requires to guarantee logistics, rules of coexistence and daily maintenance.

After the necessary characterization of the physical spaces and requirements of the NUFASIR structure, essential to be able to establish an adequate staff; then you can move on to a proposal for a workforce for NUFASIR.

\section{Establishment of the Official Functions of NUFASIR}

The organization chart of any institution is a key element in its organization process, it is an instrument that reflects in a graphic and abbreviated way its structural conception, it issues guidance information of the different levels of command and subordination existing in the organization, both for the own members of the organization and visitors. In today's world, the tendency is for companies or institutions to have structures that are as flat or horizontal as possible, since these structure facilitate the management process; Since there are not so many intermediate structures, communication and command processes are streamlined, gaining in efficiency [1].

NUFASIR Organization Chart Proposal

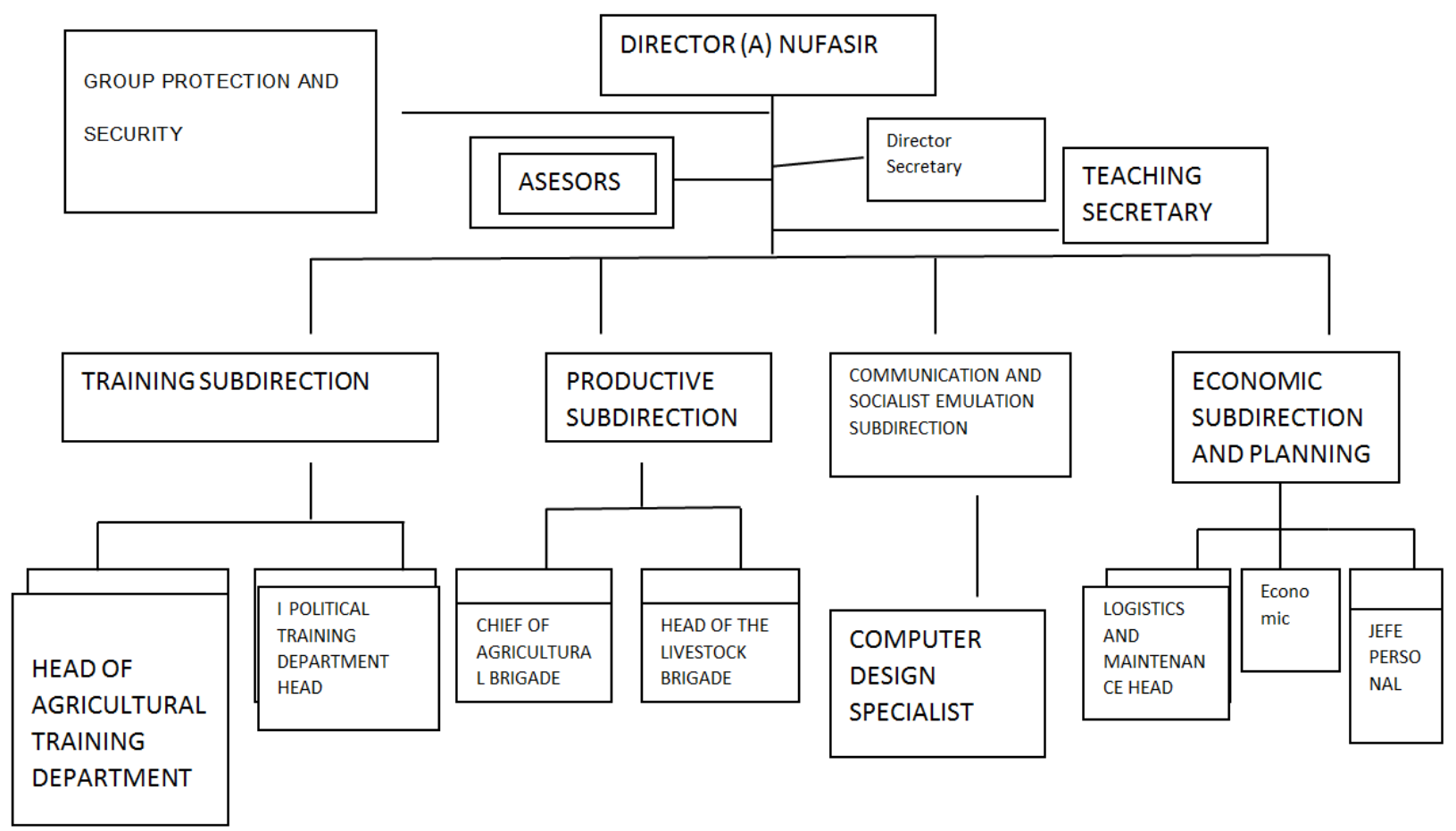

Figure 1. NUFASIR Organization Chart Proposal.

The qualifier of positions and functions constitutes a necessary element for consultation by the directors of an 
institution $[3,9]$.

Since it allows them to orient themselves in any doubt about the functions at all levels of management or execution of a work activity, it also helps in a certain conflict or noncompliance with an orientation or task to delimit responsibility. It is necessary that it be taken into account when carrying out the process of hiring a worker, since in the legal document that is signed by each party a description of the functions of the position to be filled must appear, in this way and the Future worker will have in advance all information of his future functions, setting responsibility when accepting this document with his signature. In addition to constituting an element of judgment at the time of a disciplinary analysis process $[1,4,10]$.

Proposal of the qualifier of positions and functions in NUFASIR.

NUFASIR Director: Higher level in the NUFASIR command scale, participates and is the maximum responsible for all the phases that occur in a management process (planning, organization, leadership and control) ${ }^{[4]}$. $\mathrm{He}$ is the visible external face of the institution, spends part of his time in actions related to other institutions and publicity of his institution, guarantees the management and rational use of human, material and financial resources made available by the state, as an authority he deserves respect and compliance by his Subordinates, guarantees the fulfillment of goals and objectives set by and for his organization, presides over his board of directors and guarantees its functioning, reports to higher authorities, both at political and administrative level, must have technical or superior training, He must show aptitudes and attitudes towards the position and functions he performs.

Director's Secretary: Is subordinate solely and exclusively to the director is a point of contact between the director and other members of the board of directors and workers in general, is in charge of keeping the director's personal and work agenda, guarantees the organization, aesthetics and cleanliness of the director's office, writes, organizes, facilitates and controls all the documents inherent to the actions of the director and board of directors, organizes and directs all the meeting protocol in the management room, is responsible for disseminating information authorized by The director must be a reliable person, with a high level of detachment, good manners, of good physical appearance, with good writing, penmanship and spelling, mastery of typing and computer techniques, with an unquestionable commitment to the institution and the revolution, of prestige before his co-workers and society. Preferably upper or higher middle level. He is accountable for his management to the director. Good-natured $[4,5]$.

\section{Establishment of Methodology for the Planning and Control of Work in the NUFASIR}

\subsection{Planning}

Planning is the cornerstone of any management process, locating human, material and financial resources in the right place and time requires extensive knowledge of the activity being carried out, as well as a process of careful team analysis, This depends on whether the objectives or goals set can be achieved in an efficient way $[1,5]$.

As previously stated, the first thing that must be defined is: NUFASIR's Mission, Vision and Strategic Objectives, for a determined period of time. All this, together with the necessary diagnosis carried out, allows defining the strategy that the institution must follow to continue moving forward. Regarding the Mission and Vision of this nucleus, it is very well defined at two moments in the process of construction of the Venezuelan socialist revolution: the first, when the Supreme Commander of the Bolivarian Revolution, in 2009, in his program Aló President 335, states... "This old latifundium has been liberated, now it is everyone's land, social property, and this school that is built here as a youth camp for the Miranda Front, socio-political training, training for productive work, for socialist society, is an essential part And I want to underline it just as one underlines things, an essential part of the transition, of capitalism, from which we are just beginning to move towards socialism, the path: the socialist Revolution. The objective? National independence and turn Venezuela into a power in this Continent. "The second moment, when in 2017 President Nicolás Maduro Moro, on a visit to the nucleus, delivered financial resources that allow a set of economic investments in productive infrastructure and thanks to the permanent support of President Nicolas Maduro Moros, creating conditions so that from the year 2018 a stage of extension of the results can be glimpsed that contribute to maintaining a momentum of sovereign local productive agrifood activation on a national scale.

\subsubsection{NUFASIR Mission}

The Indio Rangel Socialist Agroecological Formation nucleus constitutes a value in the formation of human resources for the socio-political and productive work of young social fighters, applying a conception of training and Figure 2 production, guaranteeing the generation of human and financial resources that allow their expansion to more states in the country, for this it has a work group committed to the policies of the revolution.

\subsubsection{NUFASIR Vision}

The Indio Rangel Socialist Agroecological Training nucleus will achieve a faculty of excellence teachers, which will allow it to be distinguished at the national level in the training of human resources for socio-political and productive work at the commune level. We are the leading nucleus in the teaching and transfer of agroecological technologies, with a sustainable projection, achieving the motivation of all our workers and enabling high levels of efficiency at work.

\subsubsection{Strategic Objectives}

1. Contribute to the politico-ideological formation of social fighters, constituting a spearhead, at the communal level, in the defense of the conquests of the Bolivarian Revolution. 
2. Develop a sustainable agroecological productive infrastructure that guarantees a training process in the agricultural sphere of quality in the medium term.

All of the above is reflected in an executing document, the work plans, both at an institutional and personal level, constitute an element of execution and analysis required by the institutional directorates to be able to trace the path towards the planned goals or objectives [3], once establishing and negotiating a work plan becomes a moral, labor and judicial commitment of the executor of that plan before his superior level of command. Due to saving resources and time, they must be carried out on a monthly basis and must have the following format:

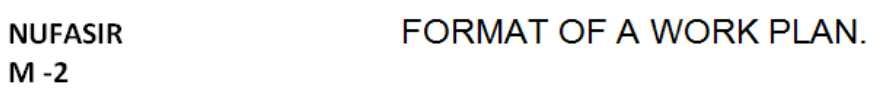

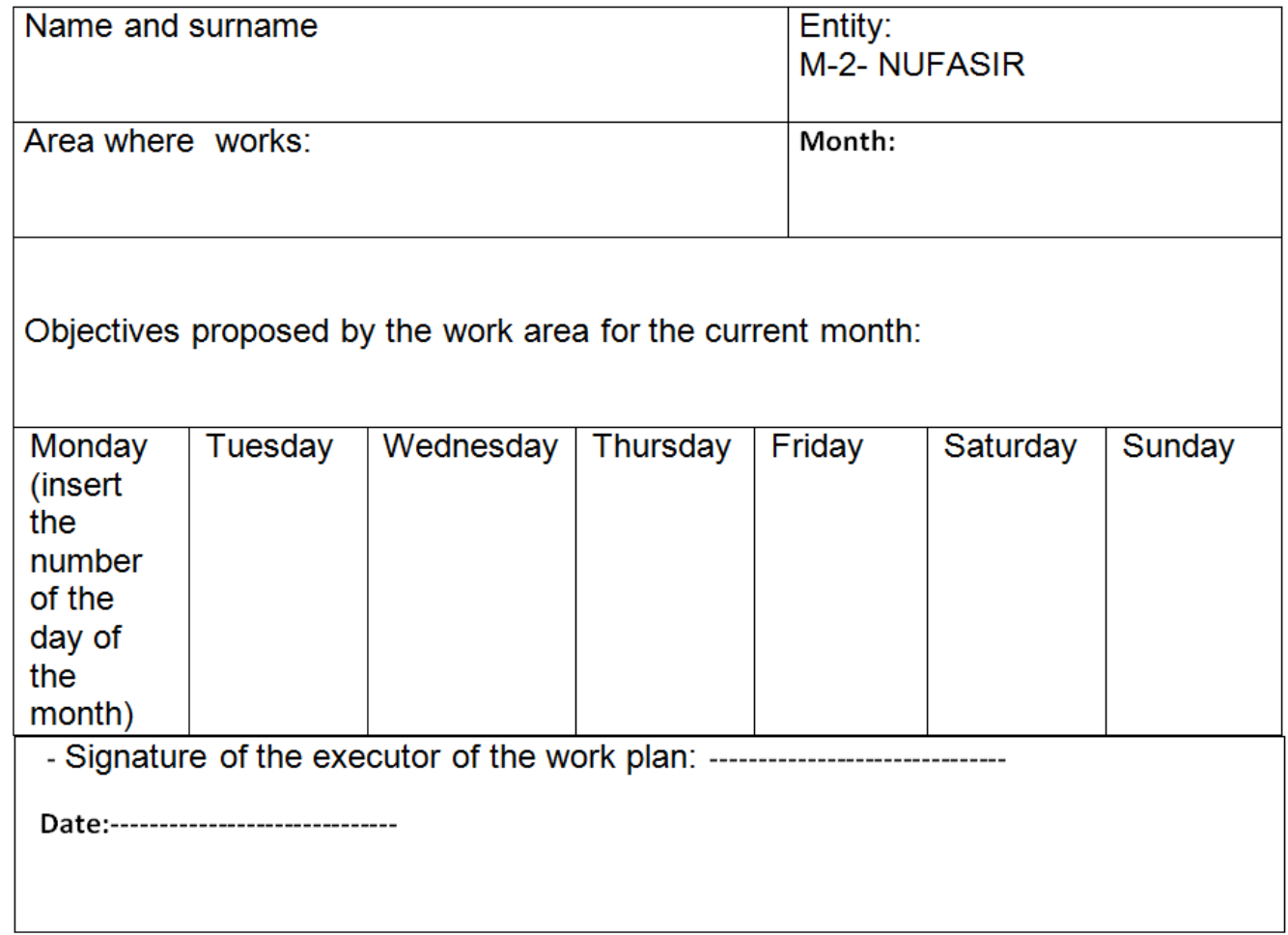

Figure 2. Format of a Work Plan.

\subsection{Control}

Control is a stage of the management process that allows correcting any distortion in action from planning to the achievement of goals or objectives, so to achieve an efficient management process it is highly advisable to carry it out systematically, not Doing so can be very dangerous because you would be missing the reality of what is happening and valuable reaction time, which in the latter case could minimize or eliminate in a timely manner the damage that could arise from any deviation from the correct path $[1,3]$.

In the control process, essential allies are the set of tools that help administrations to correct any deviation of the resources destined to the achievement of the goals set, specifically in the case of the use of humans, the evaluation of the work performance of the workers allows to have an objective vision of reality, establish a personal differentiation in the efficiency of the results achieved, this is well defined in Article 23 of the LOTTT, where it is clear that one of the basic principles for the administration of justice in A labor dispute results in the suitability of the worker, and in order to establish a suitability process in an adequate manner, it is vital to have an accurate performance evaluation of each of the workers of an institution [2].

Article 23

Principles of the administration of justice

The procedural legislation, the organization of the courts and the administration of labor, will be oriented with the purpose of offering workers, employers and employers, the solution of conflicts over individual or collective rights that arise between them, through a administration of justice guided by the principles of uniformity, brevity, gratuitousness, speed, orality, immediacy, concentration, priority of the reality of the facts, equity, rectory of the judge in the process, simplicity, efficiency, accessibility, impartiality, suitability, transparency, autonomy, independence, responsibility, attending to due process, without undue delay, without unnecessary formalities or replacements $[7,13]$.

Here are some of the new approaches to evaluating worker performance today:

-Performance evaluation $360^{\circ}$. 
-Performance software.

-Labour coaching.

-Self appraisal.

Based on the objective and subjective conditions that NUFASIR workers have today, it was decided to apply the self-assessment approach, but based on a guide of questions that is provided to the worker, here is one of the novelties of

Model for performance evaluation in NUFASIR. this manual, since In this guide, the interests of the institution are balanced with the reality in the actions carried out by the worker in his position [12].

The following is a proposal for a model for the evaluation of individual performance in NUFASIR.

Name and Surname of the Evaluated:

ID \#:

NUFASIR Work Area:

Period to be evaluated:

Name and Surname of the Head of the Work Area:

School level of the evaluated:

Aspects to evaluate:

1. Discipline.

1.1 Attendance at work

Punctuality for work.

Use of working hours.

Productivity in workday.

Quality of the work done.

Respect for superiors,

1.2 Compliance with rules of coexistence and internal regulations,

Others.

2. Political.

2.1. Participation in Civic Monday.

2.2. Participation in tasks oriented by the revolution and the FFM,

2.3. Level of relevance to the center.

\section{Establishment of Rules, Conditions and Process of Contracting for Entering the NUFASIR}

NUFASIR has within its mission the training of human resources for the socio-political and productive work of young social fighters, applying a conception of training and production, analyzing this mission, anyone could realize that the nature of this institution is typical of A school, in addition to the infrastructure that it has in operation, supports it, so that the people who enter to work in it, regardless of the position or position they occupy, is an educator par excellence, hence this peculiarity must be had very present, NUFASIR must include people capable of training and educating the new generations in the most elementary principles of a socialist revolution, in the formation of ethical and moral values that the new Venezuelan society demands, in the knowledge of agricultural production techniques sustainable and sustainable, not deform and destroy.

That is why the following methodology is proposed to achieve a quality entry to NUFASIR:

I. Step 1: Creation of an Entrance Commission or Selection Panel..

II. Step 2: Disclosure by the means that are considered necessary of the availability of the place or places to occupy in the center, as well as the requirements and conditions necessary to occupy it.

III. Step 3. In the selection of candidates.

IV. Step 4: Once the place is granted.

Hiring process

This is a very technical and legal process, where the LOTT must be taken into account when it is carried out, there are several articles within it that must be studied, but we will refer to those that appear below [2]:

Article 26

Right to work and duty to work

Everyone has the right to work and the duty to work according to his abilities and aptitudes, and to obtain a 
productive occupation, duly paid, that provides him with a dignified and decent existence.

In the part underlines it is clear that the right to work and the duty to work is according to their capacities and aptitudes and this must be clarified in the contract document, for which the existence of a qualifier of positions and functions is necessary.; since not having those capacities and aptitudes reflected in said qualifier becomes an isofact invalidating to occupy the place.

Article 79

Good cause for dismissal

The following facts of the worker will be justified causes of dismissal:

We want to return to the part of the preparation of the contract, the real name of the position or position to be occupied must be very well reflected in it, terms that leave room for doubt can not be accepted, or not reflect the functions or tasks that The contracted party must assume as its work content, observe in the content of Article 79, which appears previously where the grounds for the dismissal of a worker are wielded, which is implicitly within the clauses of a contract, and that we have underlined, as abandonment of work, and specifically within the elements that are technically considered abandonment, section b), which states: The refusal to work on the tasks to which it has been assigned, provided that they agree with the respective contract or with the Law, here the need for a qualifier of position and functions is reaffirmed, so that the contract can clearly detail which ones are the functions or tasks that the contracted party will perform in the position or position that they will occupy and thus avoid any evasion of responsibility by the contracted party due to a technical permissibility in the preparation of the contract itself.

Another key aspect in the preparation of the employment contract, and which must be very well drafted and fixed in the body thereof, are the working conditions to which the contracted party will be subjected in the execution of the position or position for which is contracted, in this particular aspect it is necessary to refer again to the LOTTT, specifically Articles 156 and 157 [2].

\section{Establishment of Labor Protection and Hygiene Standards in the NUFASIR}

For every institution, having standards of protection and hygiene at work results in full guarantees in the correct functioning of all the tasks and functions that each of its members perform during the working day $[5,6]$, since in the first place, when there is an adequate signs and rules that establish the behavior and procedure when handling tools, instruments and work machines, could minimize or avoid costly accidents at work, which can mutilate or simply end the life of a worker, secondly, the rules hygiene, for example: They are decisive in areas as sensitive as the kitchen of an institution, the violation of one of them, could in the best of cases trigger a contamination of a food with the respective medical consequences for each of the consumers.

In this sense, the LOTTT, in the aforementioned Article 156 , dedicated to mandatory conditions when carrying out any contracting process for the performance of labor activity in the Bolivarian Republic of Venezuela, specifically in its subsection e), establishes the obligation of protection of life, health and occupational safety. Therefore, it leaves each institution for granted to have a set of rules or regulations, tempered to the requirements of each position or position that responds to their own labor needs. On the other hand, Article 177, of the LOTTT, confers powers on the national authorities to reduce the working day for reasons of health or safety at work, reaffirming the protectionist nature that this law has for the worker [2].

Article 177

Shorter working hours for health and safety reasons at work

The National Executive may, in the regulations of this Law or by special resolution, set a shorter working day for those jobs that require excessive effort or are carried out in conditions of risk to the health and safety of workers.

In this case, NUFASIR has drawn up its own labor protection and hygiene regulations, which conform to international standards, to the requirements established in this regard at the national level, and to its own requirements.

\subsection{Labor Protection Rules for NUFASIR}

General (Only Some of the Established Measures will Be Exposed)

1. All areas where there are power outlets, switches, breakers, current registers, or any electrical accessory, they must be in good condition, comply with all the technical parameters established for their operation, in addition to having a visual danger signal. and the voltage that it emits.

2. All stair area must comply with its handrail and complete steps, in case of not complying with this they must be closed to the passage and with the respective signage that indicates the prohibited passage to it.

3. The areas that emit noise, above the decibels permissible for the human ear, due to the operation of their machines, must have protective devices for each of the workers who work in these spaces.

4. The areas where cutting and welding machines operate, with turning systems, among others, the workers must have the protective clothing established for each specific function, in addition to masks, special boots, the hair must remain collected all the time.

5. Work tools such as scardilla, machetes, picks, among others, must have an adequate sharpening and in appropriate fittings.

6. All work areas must have good lighting, ventilation, there should be no isolation of people and with spaces that facilitate good movement, the tasks that require their performance in night spaces, must have good artificial lighting.

7. Personnel systematically exposed to the influence of 
chemical substances should be frequently evaluated by specialized medical personnel.

8. All personnel who work at NUFASIR must be guaranteed full payment of their salary, with all the guarantees and rights of remuneration for the activity carried out according to LOTTT [2].

9. All personnel who work at NUFASIR must be guaranteed the enjoyment of their annual vacations, with all the guarantees and rights of remuneration for the activity they carry out according to LOTTT [2].

10.In the event of a labor dispute, the provisions of the LOTT T, in its Articles 493, 494, 495 and 496, will apply [2].

Article 493

\subsection{Arbitration Board}

In the event that a collective dispute is submitted to arbitration, an arbitration board will be set up, made up of three members. One or one of them will be chosen by the employers from a list of three presented by the workers; another will be chosen by the workers from a list presented by the employers and the third or third will be chosen by mutual agreement. In the event that there is no agreement for the appointment within a period of five continuous days, the Inspector or Labor Inspector will designate the representatives.

The members of the Arbitration Board may not be people directly related to the parties in conflict, or linked to them by family ties within the fourth degree of consanguinity or second degree of affinity.

The nomination will be accompanied by a statement submitted by the candidates who will accept the position in case of being elected; The same will be done, if there is no agreement on the appointment of the third referee.

Article 494

\section{i. Decisions of the Arbitration Board}

The arbitration board constituted according to the previous article will be chaired by the third or third member of the same and will meet on the date, time and place that he or she indicates.

The decisions of the arbitration board will be taken by majority vote.

Article 495

\section{ii. Powers of the Arbitration Board}

The arbitration board will have the same investigative power as an ordinary court and its hearings will be public.

The members of the arbitration board will have the character of arbitrator arbitrators and their decisions will be final.

The right of the parties to go to the labor courts to request that their nullity be declared, when the decisions of the arbitrators are taken in contravention of legal provisions of public order, is safeguarded.

Article 496

iii. Arbitration Award

The arbitration award must be issued within thirty days following the date on which the arbitration board was constituted. However, the board may extend this period up to thirty days. The award will be published in the Official Gazette and will be mandatory for the parties.

\section{iv. Prootocol for Security Personnel in the NUFASIR}

Rationale

NUFASIR has proposed to be an instance that promotes active and co-responsible participation through the establishment of norms with a humanistic sense, it is the objective that we set ourselves to preserve the physical integrity and state assets, guaranteeing their harmony and security with the linking of a internal protection system, promoting constant training that strengthens security [14].

\subsection{Labor Hygiene Standards for the NUFASIR}

In this sense, the standards presented in the current manual are in line with those stated in other manuals that address this issue.

General

1. Not talking when eating food in the dining room.

2. In each work area there must be trash cans with their respective covers and identification.

3. There should be no domestic animals roaming in bedrooms, dining room areas, or other areas of collective use within the institution.

4. The personnel who work in the kitchen must wear their respective uniform with a hat and mask or mask.

5. There must be a hand washing area at the entrance or exit of the dining room that is provided with soap and towels to facilitate the hand washing of the guests, before and after going to the food consumption area.

6. There must be an area of bathrooms and sanitary services, for both sexes, previously identified, with all the necessary supplies.

7. The food processing and positioning area must be innocuous.

8. A daily sampling of the food and water ingested within the facility must be carried out and its subsequent certification as suitable for human consumption.

9. The consumption of cigarettes and alcoholic beverages during working hours in the areas of the facility is prohibited.

10. It is prohibited to work in areas of the kitchen dining room with colds, or any contagious disease or wounds or ulcerations on the skin.

11. It is prohibited to work in any area of the nucleus with any disease that limits their work performance or infectious contagion.

12. The use of base stations or music equipment should be restricted to specific hours for the recreation of workers and with audio levels that do not exceed the decibels supported by the human ear.

13. There must be a laundry area that guarantees quality services to the personnel housed in the institution.

14. There must be and guarantee the proper functioning of the wastewater evacuation and treatment services. 


\section{Establishment of the Disciplinary Regulation and Sanctions in the NUFASIR}

In Title I of the LOTTT: Constitutional norms and principles, the incorporation of guarantees of application of the law is established by granting the administrative and judicial authorities empowered to achieve that their administrative or judicial decisions restore the infringed legal situation of a labor nature, including the use of public force, in those situations that may warrant it. It also streamlines and simplifies the administration of labor justice, and also establishes the objective responsibility of the employer in relation to the guarantees that the law requires with its workers and with the country, with special emphasis on health and job security. It is precisely derived from all the above that it is necessary to have a disciplinary norm or regulation that regulates the behavior of workers within the institutions, making clear what their duties and rights are, speeding up and simplifying the administration of labor justice [2].

\subsection{NUFASIR Disciplinary Regulation}

In Title IX of the LOTTT it is established that the procedure for the sanction will be carried out in strict protection of the principles of legality, the right to defense, rationality, proportionality and typicality. On the other hand, in Title IX, Article 521, it states: Violations of the provisions of this Law will be subject to the sanctions established in this Title, without prejudice to the administrative, civil and criminal actions that may arise.

In order to facilitate an adequate behavior of the work forces within the nucleus, attached to the fulfillment of the most elementary norms of labor coexistence that regulate the Constitution of the Bolivarian Republic of Venezuela and the LOTTT, in addition to norms and principles that regulate the actions of the members of the Francisco de Miranda Front, within the organization's own facilities, as well as the demands of a political, social and business order imposed by the process of building socialism in the Bolivarian Republic of Venezuela is that the need for the existence of a disciplinary regulation in this institution, which clearly shows the duties and rights of the workers that are part of it, and the internal rules that will guarantee the fulfillment of these duties and rights, achieving the materialization of the aspirations labor embodied in the LOTTT and in the constitution of the republic itself [2].

\subsubsection{Duties of a Worker at NUFASIR}

1. Unconditional respect for the symbols of the homeland and the Francisco de Miranda Front.

2. Respect and unconditional support for all the processes that are carried out in the construction of socialism in the Bolivarian Republic of Venezuela.

3. Recognition and compliance with the authority of his superiors.
4. Practice of values such as honesty, fraternity, simplicity and combativeness to what is badly done.

5. Compliance with the working day.

6. Efficient use of the material and financial resources made available to them in their daily tasks.

7. Care and protection of the material and financial resources made available to them in their daily tasks.

8. Knowledge of and compliance with all regulatory norms of behavior and labor discipline within the institution.

9. Knowledge and fulfillment of their functions and work content.

10. Carry identification documents required for the institution or job.

11. Know and comply with the requirements for their position of the standards of protection and hygiene at work.

12. Daily attendance and punctuality at your job.

13. Participate in voluntary activities called by the management of the institution outside of working hours.

14. Keep your medical record or health card updated.

15. Know and respect the levels of access to areas and offices within the institution.

16. Participate in meetings called by the different levels of management existing in the institution.

17. Do not take and transport out of the institution items obtained in the production process without prior authorization from their managers.

18. Not to disclose information on the work activity carried out or on the institution without prior authorization from its leaders.

19. Do not smoke or drink alcoholic beverages during working hours.

20.Comply with the schedules, standards of conduct and dress stipulated for the dining area.

21. Respect the schedule set as silence for the rest of the sheltered staff.

Rights of a Worker at NUFASIR

1. A member of the military in a union of free choice.

2. To enjoy all the social security guarantees established by the LOTTT [2].

3. To receive a fair remuneration for the work that he performs and that contains all the bonanzas established by the LOTTT [2] for each case.

4. To enjoy their annual vacations with their respective remuneration as established by the LOTTT [2].

5. To be guaranteed the requirements of protection and hygiene at work demanded by his job and the work he performs.

6. That the management of the center guarantee the training process in specific topics chosen by the worker or directed by the institution itself.

7. Not to be discriminated against because of his race or sex.

8. Not to be sexually harassed.

9. To file an appeal before the pertinent authorities after 
the application of a sanction measure for a violation of labor discipline.

10. Right to strike, in all its expressions.

11. Right to free expression.

12. Right to speak in meetings at all levels.

13. To have their work functions, work content, schedules to be met, protection conditions and work hygiene, among others, appear in their employment contract.

14. To exercise moonlighting.

\subsubsection{The Following Are Considered Less Serious}

Violations of the Duties of the Workers in NUFASIR

1. Disclosing information about your job or the institution without authorization from the directors, which does not compromise the stability, permanence or relationships of the institution.

2. Unjustifiably missing a number of meetings, which does not exceed more than $10 \%$ of those called, by the different levels of management of the institution.

3. Ignoring or entering restricted access areas in the center unintentionally, during daytime hours and that does not endanger the lives of the people who occupy them or the physical integrity of the material or financial resources found sheltered in those places.

The LOTTT does not include penalties based on the level of the violation committed; However, if it establishes the entire legal framework to guarantee the protection of workers and the proper functioning of administrations, that is why in this manual we have considered pertinent the division of violations committed by workers in their duties, into two levels: less serious and very serious, in the case of the former, with the application of the same it is intended to have an educational effect on the worker, which helps him to recognize the fault committed, to reflect on the possible consequences of the same on his person, about the institution and about society. In the case of the second category of sanctions, very serious, as they are typified in the LOTTT, their only way out is the breaking of the employment relationship established between the worker and the institution. For both categories of sanctions, the principles of legality, the right to defense, rationality, proportionality and typicality included in the LOTTT apply [2]

We do not refer to the violation of the worker's rights, because all those that appear previously reflected are included in the LOTTT [2], and in this law it is clearly established that those rights are of mandatory compliance by the institutions, and that their violation It guarantees the worker to establish demands before all the existing governmental and legal levels.

Sanctions established for less serious violations of the duties of workers in the fulfillment of their functions and work content in NUFASIR.

The commission by a worker of a less serious violation of the duties established in the performance of functions and fulfillment of their work content during a working day at NUFASIR has two moments:

First: Notification by his immediate superior boss, in the chain of command in the institution, of the violation committed and its corresponding private reprimand, leaving a written record of the entire procedure, with the signature of the offender and the one who admonishes, and date of execution and its subsequent reflection in the evaluation of the worker's performance in the current month.

Second: In case of recurrence of the worker for more than three times in the same offense, the management of the institution reserves the right to establish an analysis that allows it, as established by the LOTTT [2], to adopt another type of disciplinary measure of greater rigor with the offender. Guaranteeing in this way the due process to which a worker is entitled.

\subsubsection{Appeal Procedure by the Worker}

In the case of the commission of a worker of a less serious violation, regardless of his degree of recidivism or not, he may establish an appeal before a commission designated for this purpose by the management of the center, for this he must deliver in writing to the head of the commission created a request for complaint and disagreement with the sanction imposed, within a period of 7 business days after the sanction has been imposed, failure to do so in this period would render the right to appeal without effect. In this body of the report he must address all the details that he considers appropriate to prove his innocence.

The commission will be made up of 3 members, one appointed by the management of the center, another by the majority of the workers and a third by common agreement between management and workers, the latter must be the head of the commission. Once the appeal filed by the worker has been accepted, the commission will have a period of 30 working days to study, observe evidence and rule on the origin or not of the appeal made by the worker, in the event that the sanction is on a cause of non-recidivism that culminates with a private reprimand by the immediate superior boss about the commissioner of the violation and its indication in the performance evaluation of that current month, the decision by the commission is final, in the event that the worker is reoffending and the result of the sanction is a change of job to one with lower remuneration, a fine or permanent separation from the labor entity; Then, if the positive ruling on the sanction selected and imposed on the offender is ratified by the designated commission, he may appeal to the different levels established by the LOTTT for such purposes [2].

\subsection{The Following Are Considered very Serious Violations of the Duties of the Workers in NUFASIR}

1. Disrespect or outrage to the symbols of the homeland and the Francisco de Miranda Front.

2. Non-recognition and compliance with the authority of his superiors.

3. Repeated non-compliance with the working day.

In the case of a worker incurring in one of the above violations, considered very serious and which are equated to those provided for in Articles 77 and 79, of the LOTTT [2], as justified causes, the management of the center is 
guaranteed the option of dismissal.

\section{Stimulation System for the NUFASIR}

The LOTTT [2] promotes and protects popular initiative at work, facilitating the development of socially owned work entities and any other form of community association for work managed in a participatory and leading way by workers. It also proposes raising the standard of living of the population and strengthening the economic sovereignty of the country, as well as promoting and stimulating among its affiliates ethical, moral and human values that allow a fair distribution of wealth, a national productive consciousness, sustainable development at the service of society, food security of the population and placing the supreme interests of the nation and the sovereign people, above individual interests.

In what appears in bold and underlined in the previous paragraph, a group of aspirations typical of a socialist social system are synthesized, being more than studied and demonstrated in its construction the need for a system of stimulation to the practical and effective worker, which together with the role that salary plays within this type of society, becomes a motivating spark plug, thus allowing the achievement of the aforementioned aspirations [6]. We emphasize a practical and effective stimulation system, because if it were not, far from fulfilling its objective of motivating the work, it could become the opposite, unleashing negative consequences for the entities and being a serious brake on the progress of construction of socialism.

In NUFASIR, a diagnosis has been carried out by its managers in order to draw up a management strategy that allows to quickly and safely achieve the objectives or goals proposed in the short, medium and long term, throwing the same into its weaknesses the lack motivation of its workers, after several analyzes, and knowing the threat existing in Venezuelan society of a serious economic inflation, where the bolivar depreciates every day more against a dollar, and the role of the salary earned by a worker leaves every day more than playing its role, it is necessary to search for alternatives that encourage work, being the application of additional possibilities of material stimuli a way to keep the productive forces motivated.

Here it is very necessary to analyze the labor operation of the entities as a system; and to achieve the effectiveness of this system, it is mandatory to have a personalized performance evaluation, which has a systematic nature and adjusted to the real context in which the worker moves, this will make it possible to properly distinguish the results of the work, materially stimulating those who really deserve it, turning the stimulus into a formator of values, a desire of each worker, which at the same time would raise the results and achieve a productive conscience [3].

Proposed methodology for the achievement of a stimulation system in NUFASIR.

1. Existence of a monthly performance evaluation.
2. Conduct monthly performance evaluation.

3. Choice of workers to stimulate by area.

4. Material and financial resources destined to stimulate workers by the different areas of NUFASIR.

In order to achieve a stimulating and sustainable material or financial stimulation system, it is vital to properly plan these resources, and to achieve production levels that allow surpluses, which can, without affecting the entity's commitments, be used to stimulate its workers, so that the efficiency of work in the agricultural areas of the institution will become the engine that generates the resources allocated to such endeavor. Given the current situation in the Bolivarian Republic of Venezuela, in the midst of a growing economic blockade by the main hegemonic power in the world, together with a ruthless inflation of its currency, they constitute two of the fundamental elements to consider and justify the need for an additional work stimulation system in each entity, which allows stability and better results of the work force available to each one. Therefore, a good incentive could be the combination of the financial stimulus with the material, for example: $10 \%$ of the money received from sales of the institution's productions could be allocated for the preparation of a budget that would be divided equally between each one of the stimulated, and would be accompanied with $10 \%$ of the surplus production, of the agricultural products obtained that month.

\section{Delimitation of Areas and Levels of Responsibility and Access by Labor Areas of NUFASIR}

The process of delimiting work areas within an entity is included in the natural process of work organization in any company or institution $[1,6]$, the creation of departments, is the basic expression of work organization at the level of a company. The number of departments or work areas is not conditioned to a quantitative expression, it depends on the own needs that a given entity has, for an adequate operation.

Material responsibility is of great importance for each institution and for the economy of a country since it allows maintaining an attitude consistent with the principles of society and guaranteeing the preservation and care of the material, economic and financial resources of labor entities [6].

What should be very clear is that regardless of the number of work areas or departments that an entity has, whatever it may be, they must all function as a system. It is the only way to achieve a harmonious and efficient development of the entity.

In the case of NUFASIR, Sub-directorates have been defined: Training, Agricultural Production, Economic and Planning and Communication and Socialist Emulation, which in turn are divided into the corresponding departments and these in the respective work areas, See NUFASIR Organization Chart, Chapter 3, of this manual, these subdirectorates and departments are tempered to the 
structural conditions, available personnel and strategic objectives, proposed by this entity for the current period in which it is located.

Dividing the work in an entity by levels of specialization, specific functions and purposes or goals, has been a daily practice in business work, since it allows the efficient fulfillment of the proposed tasks [6]. At the time that the qualifier of positions and functions and organization chart was established, which appears in Chapter 3, a first approach appears to the delimitation of the necessary areas, according to the objectives proposed by this entity, which is not a dogma; since the number of areas or departments that this entity has today, do not necessarily have to be the ones it will have tomorrow.

\subsection{Methodology for the Creation of Areas of Responsibility and Access Levels in NUFASIR}

1. Definition of the area of.

2. Delimitation of the areas of responsibility.

Appointment of the Head of the Area: For this step, the person who is also the head of the physical space management and all the resources, material, financial and human available to it, must be chosen, since their attitudes and aptitudes, many of which are described in the job and function qualifier, which appears in Chapter 3 of this manual, make him an ideal person to face this responsibility. This process of appointing the person in charge will be carried out under the protection of an internal resolution made by the Board of Directors of the entity, leaving the entire process reflected in the minutes and filed in the aforementioned file formed in the previous step.

\subsubsection{Survey of Tools, Tangible and Useful Fixed Assets Available to the Area of Responsibility}

Two people participate in this step, the appointed Head of the Responsibility Area and the Deputy Director of Economy and Planning, a record will be drawn up where the amount of the assets, tangible fixed assets, tools and supplies that are assigned to the area, the minutes being signed by both persons and filed and guarded in the file that has been conformed from the previous steps and which appears under the protection of the highest management of the center. Here, at this point, it should be said that a systematic review by the two responsible parties mentioned above is necessary of the physical integrity of each asset, tool or useful that the area has, leaving each audit process reflected in minutes and files do In the file formed for this purpose, this will guarantee to prevent any loss or diversion of material or financial resources that have been assigned to the area in question for its proper functioning.

\subsubsection{Material Responsibility in the Area}

This is a fundamental premise, for the proper functioning of the area and of the entity in a general sense, it is about defining the maximum responsibility in the custody and maintenance of the material and financial resources destined for the correct operation of the area, you must start from the beginning in direction, the responsibility is not delegated or transferred, as previously stated, the manager in charge of that area is also responsible for the material and financial means that have been assigned to that area for its correct operation, so that at the same time it assumes that responsibility as its highest representative, although all people who have access to or work in that area are also responsible for the care and preservation of these media. Once it is determined by the management of the center that one or more persons have incurred in violations of labor discipline, which have as a consequence the loss or damage to an asset in their custody or work, as established in the LOTTT, in its Article 79, Subsection g), constitutes a condition for keeping a worker or manager in his or her job position, this without counting, that due to the magnitude of the damage, other collateral measures such as fines or made available to the corresponding courts for the administration of justice [2].

\subsubsection{Definition of the Levels of Access to Areas of Responsibility}

It is advisable to avoid the access of people outside the area, either from outside the entity or from other areas within the entity itself to a specific area of responsibility, it constitutes a basic element in prevention, avoiding loss of financial or material resources available in the area, as well as the corresponding loss of time, which generally cause this type of interruption, it is advisable to have an identifier of accessibility to the area in a visible space, where it is reflected who or who can access that area and if there are schedules to do so. An act must be drawn up signed by the Head of the Responsibility Area where this access protocol is declared and who can access the area, establishing the levels of access to this area, said act will be filed for safekeeping in the file that has been conforming for this purpose and that will be preserved by the maximum direction of the center.

\subsubsection{Custody of Keys and Seals of the Different Areas of Responsibility of NUFASIR}

As a preventive measure, it is recommended that in the local or exit checkpoint intended for the prevention of the center there is an iron box with a stamp where a coupling appears with an identifier for each of the keys of each premises of the institution or area of responsibility, being the responsibility of each area manager, once the daily working day is over, the delivery of their key which will be deposited in this box and sealed with an official seal of the person in charge of each area, and then the box will be closed and sealed with the official seal of the highest management of the center, being reflected in the prevention incident book all this procedure and if any premises that have not been delivered are missing and why, being the those most responsible for the custody of the keys and their sealing by the prevention agents who are on duty, making delivery every time they e there is a renewal of this procedure, in case one of the seals has to be broken due to fire or other reasons before the scheduled time for the extraction of the keys, in the following working day, it 
must be reflected in the book of incidence of who, the time and why did it, assuming that person in the company of the prevention agents the custody of open premises and keys, until they have been closed again with all the guarantees of security and integrity of the media that are inside them, the keys or keys extracted for this reason being in custody and sealed again.

\subsection{Control and Execution of This Methodology}

In order to guarantee the execution and control of this methodology, it was established within the functions of the NUFASIR Head of Security, to guarantee the care and protection of all material goods found within each premises of the entity, for this purpose the same Together with the person in charge of each area, after each working day they will carry out a delivery and receipt process, where the head of each area will deliver the goods that are in their area of responsibility to the head of security, this will be recorded in writing and under signatures of both, keeping the security chief the key of the area in question in the already mentioned key drawer, created for these functions, which will be sealed with the official seal of the head of the area of responsibility, this seal can only be broken in case accident or emergency, which must be well documented in the incident book companies created for this purpose, being the entire responsibility of the head of security and his group, the custody of keys and goods placed under his responsibility in the night period, in the morning this same process is carried out, but in the opposite direction of the head of security towards the area manager, in this way all the previously proposed methodology is complemented, and the preservation of all the entity's assets is fully guaranteed.

\section{Conclusions}

1. The design and preparation of this manual is unprecedented in the history of creating NUFASIR.

2. It constitutes an essential methodological and operational tool for the organization of human resources at NUFASIR.

3. It contributes to a more efficient functioning of human resources in NUFASIR, facilitating the achievement of the goals set by the institution.

4. Allow a greater humanization of work in the NUFASIR areas.

5. It contributes to the achievement of better protection and hygiene at work in NUFASIR.

6. It allows a more rational use of human, material and financial resources in NUFASIR.

7. It further strengthens the collaboration between the Bolivarian Republic of Venezuela and the Republic of Cuba, regarding the development of their human resources.

\section{References}

[1] Stoner et al. 1996. Administration. Second Edition, Volumes I and II. Harvard University. E. U.

[2] Organic Law of Labor. 2012. Male and Female WorkersOfficial Gazette No. 6,076 Extraordinary of May 7, Bolivarian Republic of Venezuela.

[3] Diamond, S. Z. 1983. How to prepare Administrative Manuals. In S. Z. MEXICO: New publisherinter-American.

[4] Krauss, M. D. 1977. Procedures manuals in offices. In M. D. Krauss, Office procedure manuals (p. 235). Mexico: National Autonomous University of Mexico.

[5] Ponce., A. R. 1983. In A. R. Ponce., Personnel Administration (p. 245).

[6] Valencia, J. R. 2002. Modern Personnel Administration. In J. R. Valencia.

[7] Constitutions Bolivarian Republic of Venezuela. 1999.

[8] Informative Manual on Occupational Risk Prevention: Organization Manual. 2017 Regional Institute of Occupational Safety and Health. Ministry of Occupational Health and Territorial Development, (p 16).. UGT-Madrid. Spain.

[9] Organization Manual of the Institute of Environmental and Ecological Sciences. 2007. (p 32). Faculty of Sciences, Universidad de los Andes, Mérida, Bolivarian Republic of Venezuela.

[10] Organization Manual of the Labor Relations Department. 2020. Centro de Integración Juvenil AC, (p13) online (accessible http://www.intranet.cij.gob.mx/Archivos/Pdf/Organizacion/O RGRELABOR.pdf

[11] How to make a manual of step-by-step procedures, structure and usefulness. Palma, J. 2020. online (accessible at) https://www.gestiopolis.com/creacion-de-un-manual-deprocedimientos/

[12] Measure your team! Learn about the latest trends in performance evaluation López, M. A. 2020. Online (accessible

https://www.crehana.com/blog/empresas/tendenciaevaluacion-desempeno/

[13] How to evaluate an employee's job performance? 2021. Online (accessible at) https://factorialhr.es/blog/desempenolaboral/.

[14] Safety and Hygiene Manual. 2019 Special Projects Unit. Interactive Ecopark of the City, Autonomous of Buenos Aiers, Argentina. online (accessible at) https://documentosboletinoficial.buenosaires.gob.ar/publico/P E-DIS-MAYEPGC-UGGOAALUPEEI-55-19-ANX.pdf

[15] Legislative Compendium of Material Responsibility. 2008. Ministry of Public Health. Republic of Cuba. online (accessible

at) http://www.dncontabilidad.sld.cu/Doc/act/manuales/no_conta bles/responsabilidad_material.pdf 